\title{
Is Chalmers' Analysis of Consciousness a Strong Alternative to Materialism?
}

\author{
Dr. Shanjendu Nath, M.A., M.Phil., Ph.D. \\ Associate Professor, Rabindrasadan Girls' College, Karimganj, Assam, India.
}

\begin{abstract}
In explaining the nature of consciousness the position of materialism and dualism are opposed to each other. Materialist philosophers explained consciousness with the help of matter. Over and above brain process, they do not believe any immaterial entities. They analyse consciousness with the help of brain process. This is undoubtedly a challenge to dualist philosophers. Chalmers, a supporter of dualism, strongly criticises the materialist analysis of consciousness and instead he tries to explain it by the theory of dualism. In this regard he used his imaginary Zombie theory. But the materialists also responded to Chalmers' arguments. In this paper I shall try to explore Chalmers' Zombie theory of consciousness and the responses of materialists against it. And finally, show that Chalmers analysis is not a stronger alternative to the materialism.
\end{abstract}

Key words: Consciousness, Eliminativists, Supervenience, Zegnet, Zombie.

\section{Introduction}

There are different mysterious things to human beings. But the most surviving and last mystery is human consciousness. Common people believe that consciousness is an illusion or mysterious thing. But this view cannot be accepted because consciousness is the surest existence that cannot be denied. Philosophers of different ages also attempted to solve the problem. But the problem is that consciousnesses is beyond our reach and as such whatever information we got from different philosophers are really probable and not certain. The materialists attempt to explain everything including consciousness with the help of matter. They do not believe any mysterious entity and thereby consciousness is not mysterious to them. According to them, both consciousness and brain processes are identical. Apart from physical processes there is nothing called consciousness. Materialist analysis of consciousness has been facing severe criticisms from Chalmers. But the materialists are not silent towards these criticisms rather they responded to the criticism.

\section{Chalmers' Analysis of Consciousness}

In his famous book The Conscious Mind Chalmers put forwards different arguments against materialist concept of consciousness. He says that materialism fails to explain the question how consciousness could amount to physical structures and processes. He opines that the eliminativists also have not taken consciousness seriously as they do not believe any phenomenon over and above brain processes and their interaction. Explaining the problem of consciousness he holds the view that if one takes consciousness seriously he will have to endorse a dualistic theory like property dualism

The problem of consciousness can be viewed from different standpoints. Among them, one important way is to think that it is an old mind-body problem that can be viewed with a new set of concepts. Moreover, in recent time there is a trend to solve the problem with a new concept called the concept of supervenience. This concept can be understood on many levels although basically it describes a dependence relation between two sets of properties- higher level properties and lower level properties. Whenever it is found that the higher level properties depend upon the lower level properties, it is said that higher level supervenience on the lower level. This concept of supervenience is very nicely explained by Chalmers. In rejecting the materialist theory of consciousness Chalmers exerted his best effort by giving different arguments. With the following two premises his argument can be summarised-

1. Consciousness is a phenomenon that exists in our world.

2. Consciousness cannot logically supervene on the physical because zombies are logically possible.

Chalmers argues that zombies are logically possible. Zombies are logically possible or not are dependent on the belief that the notion of zombie has no inherent logical contradiction. Logically, only that has possibility which does not contain any logical contradiction in its nature. There seems to be no contradiction in the idea of a zombie who is physically identical with human being but lacking conscious experiences. This possibility is also admitted by the eliminativists. But unlike Chalmers, the eliminativists believe that zombies are not only possible but also actually existent like us. Dennett, an eliminativist, does not believe the existent of any phenomenon that match with consciousness even in human being like us. He does not agree with Chalmers' 
view that an exact physical replica of a person exists but it is devoid of something that a person possesses. In this connection I may refer Dennett's view which he expresses in his book "Consciousness Explained." In chapter 12 of this book Dennett (1991) says-

"There is another way to address the possibility of zombies, and in some regards I think it is more satisfying. Are zombies possible? They are not just possible, they are actual. We are all zombies. Nobody is conscious- not in the systematically mysterious way that supports such doctrines as epiphenomenalism! I cannot prove that no such sort of consciousness exists. I also cannot prove that gremlins do not exist. The best I can do is show that there is no respectable motivation for believing in it."

Dennett, in this passage, does not deny the pain experience. His view is rather that there is nothing mysterious in what is going on in our heads about which Chalmers was worried. Thus Dennett says-

"The time has come to put the burden of proof squarely on those who persist in using the term. The philosophical sense of the term is simply ridiculous.".2

The argument which Dennett and other eliminativists put forward is that what is called by the philosophers as 'consciousness' is nothing more than a bunch of complex interaction between brain states, sensory input, and motor output that occur within our heads. This sort of things which Dennett claims and what Chalmers attributes to zombies are exactly same. But it is not a matter of fact whether a person is like a zombie or not, the materialists hold that there is an inconsistency in the logical possibility of zombies.

Dennett further says that it is totally inconceivable to have a zombie whose behaviour is exactly like us but does not possess any mental life. Searle points out that this strategy does not seem to be a very promising one on the ground that it is very easy to imagine intuitively that there is a machine which is in all respects likes us except consciousness. Dennett's argument is that someone may suppose the existence of iron bars and behaviour of this iron bars are exactly like magnets in all respects but yet not magnets. These are rather called zegnets. But an existence of zegnet, according to Dennett, is inconceivable because, this zegnet would be nothing but magnet. Thus Dennett analogically concludes that a machine whose behaviour in all respects is like a conscious agent is nothing but a conscious agent. Similarly, zegnets are nothing but magnets and zombies are nothing but conscious agents. Here philosophical intuition about the possibility or impossibility of zombies or similar sorts seems falter and the argument based on that cannot be considered as conclusive against the identity theory.

It is expected that the expansion of our knowledge of physics is possible in future and by this knowledge we will be able to see that consciousness does logically supervene on the physical, although Chalmers denied this possibility. This better understanding of physics will justify the standpoint of materialism but for which we will have to wait. Thus it can be said to Chalmers that to explain consciousness physically is to require a very different sort of physical theory than one that we have presently.

Chalmers' conclusion that consciousness cannot be explained physically is derived from the premises that zombies are logically possible and these zombies are physically identical with us except consciousness which they lack and that is why their inside is dark. He also claims that to infer the existence of consciousness in human being one's knowledge of all physical information about a person is not enough. But the materialist suspects that Chalmers equates explanation with the bottom-up process of illustrating how high level properties are produced by low level properties.

It is a fact that in the debate between physicalist and dualist the notion of reduction is very important. There is sense in which some fact is reducible to other facts when the higher fact is explained by the lower facts and Chalmers uses the term 'reduction' in this sense. From this conception Chalmers concludes that it is an impossible task to reduce consciousness to physical structure and their movements. But materialists claim that Chalmers conclusion is partially true and partially false. Because there is another sense in which the term reduction is used and this is the sense which does not appeal to the notion of explanation. It rather appeals to how our world turns out.

It is true that the materialists fail to explain consciousness. But it is also true that this is not blame only to materialists theory but all theories whoever attempted to explain it. It is because of the fact that the problem of consciousness is one of the mysterious things in the world. There are several mysteries in this world, such as the mystery of the origin of the universe, the mystery of the origin of life, the mystery of nature's design, the mystery of time and space and gravity. None can say the final answers about the question of cosmology and particle of physics, molecular genetics and evolutionary theory. Yet some of we know how to think about them. But this cannot be said about consciousness. In this connection I may refer Dennett's writing. He says,

"With consciousness, however, we are still in a terrible muddle. Consciousness stands alone today as a topic that often leaves even the most sophisticated thinkers tongue-tied and confused. And, as with all the earlier mysteries, there are many who insist-and hope-that there will never be a demystification of consciousness."”

\footnotetext{
1. I, p-406

2. Ibid., p-405
} 


\section{Materialist' Responses towards Chalmers' Analysis}

Chalmers' notion was to establish dualism for which he criticized the materialist theory. But there are possible responses from the materialist quarter against Chalmers' argument. These responses of the materialists undoubtedly offer a viable alternative to property dualism. Not only this, these responses also avoid the most counter-intuitive consequences of property dualism. The materialists put forward the argument against zombie also. Acknowledging that zombies are logically possible they hold that zombies are metaphysically impossible. In this connection I may refer an illustration given by Joseph Levine (1993) on the ground why the materialist should not be afraid of Chalmers' argument and give up their theory. Levine in his article "On Leaving Out What It's Like" (1993) points out that Chalmers' argument that zombies are logically possible is conceivable only and from this conceivable he establishes epistemic conclusion without any attempt to establish metaphysical conclusions. Only from the conceivability of zombies one yet not proves the real existence of zombies. It can at best be imagined that zombies could exist. It is Levine's claim that in order to proceed from epistemic conclusion to the metaphysical conclusion an additional step is required. And to refute materialism, this additional step is needed by an anti-physicalist. Thus by several questions Levine extends his objection against Chalmers' refutation of materialism. Some of these are-

1. How does conceivability constrain how our universe really turns out?

2. We can conceive of a zombie, but why should this conceivability limit us to instantiate consciousness? Or, in other words, it may be that it cannot be conceived by someone how consciousness could be a physical phenomenon. But from this why should it mean that consciousness cannot be physical phenomenon?

Levine admits that at present we are unable to reduce consciousness to physical processes and this inability is stated by him as explanatory gap. But this explanatory gap, according to him, does not constrain how metaphysics of our universe will turn out.

It is conceivable, according to materialist that consciousness is not a physical phenomenon but the intention behind the application of metaphysical identity to consciousness is to show that metaphysically consciousness might be identical to physical phenomena. But dissatisfying with this argument of the materialist, Chalmers points out that this response explains the contingency and at the same time it avoids the conclusion that physically consciousness cannot be instantiated. The materialist theories hold that as there is identity between water and $\mathrm{H}_{2} \mathrm{O}$, so is the case between consciousness and physical processes. Logically it is possible or conceivable that water might have been XYZ but in fact in our world water is just $\mathrm{H}_{2} \mathrm{O}$. Therefore, water refers to $\mathrm{H}_{2} \mathrm{O}$ in all possible worlds. In the same line of argument the materialists hold that consciousness is physically instantiated although it is possible to think of a zombie having physical similarities with us but devoid of consciousness. From the above the materialists conclude that the physical phenomena should be called 'consciousnesses' in all possible worlds. Thus, according to this revised version of materialism, metaphysically a zombie world is impossible although logically it is possible.

There is presumption that the materialists who believe the metaphysical identity also believe that in future there will be a conceptual revolution in physics and psychology and then we will be able to explain consciousness physically. They also believe that it will not be an impossible task for us to have a physical reduction of consciousness only after we got a true and complete theory of nature. Thus materialism cannot be refuted by Chalmers by the argument of the conceivability of zombies although we are lacking such expected revolution in physics. Moreover, the connection between consciousness and physical phenomena as a priori also cannot be admissible. We have our limitation in conceptual powers no doubt, but this limitation does not impose any further upon us to instantiate consciousness.

\section{Conclusion}

In the light of the above argument I may show a common analogy to explain the phenomenon of life. Even in hundreds years ago life were explained with the help of some miraculous vital spirit or such other substance. It was totally inconceivable to us to explain a complex phenomenon like life by the appeal to chemistry and minute particles. But now-a-day without appealing to any mysterious concepts such as, souls or vital fluid modern science is able to explain life and its reductive explanation. Thus it is the firm conviction of the materialists that a day will come when we will be able to do the same thing in respect of consciousness and the problem of consciousness will no longer be a 'hard problem' as Chalmers uttered. But if Chalmers preferred his own dualistic theory he must rule out the above response given by the materialists regarding the possibility of zombies. Here many philosophers would agree with me that the dualistic theory which he develops later must follow from the available evidence. But in order to prove that the notion of metaphysical identity of the materialist is unable to save themselves, Chalmers fails to provide a convincing argument. That is why he fails 
to establish his claim that his own theory is a stronger alternative to materialism and thereby all his endeavours to rule out materialism ends in vain.

\section{References:}

[1]. Armstrong. D.M., 'Consciousness and Causality', and 'Reply'. In Armstrong, D.M. and Malcolm. N., Consciousness and Causality, Oxford, Blackwell, 1962.

[2]. Armstrong. D.M., A Materialist Theory of the Mind, London, Routledge. Second Edition with new preface 1993, (1968a).

[3]. Armstrong. D.M., Bodily Sensations, London, Routledge, 1961.

[4]. Armstrong. D.M., Martin, C.B. and Place, U.T., Dispositions: A Debate, T. Crane (ed.), London, Routledge, 1996.

[5]. Armstrong. D.M., Perception and the Physical World, London, Routledge, 1961

[6]. Beakley. B. and Ludlow. P. (ed), The Philosophy of Mind, Classical Problems/ Contemporary Issues, New Delhi, 2007.

[7]. Chalmers. D.M., Philosophy of Mind: Classical and contemporary Readings, Oxford University Press, USA, 2002.

[8]. Chalmers. D.M., The Conscious Mind, New York, Oxford University Press, 1996.

[9]. Dennett. D.C., Consciousness Explained, Boston, Little and Brown, 1991.

[10]. Hill. C.S., Sensations: A Defense of Type Materialism, Cambridge, Cambridge University Press, 1991.

[11]. J.Searle, ,Mind, A Brief Introduction, (New York, Oxford University Press, 2004)

[12]. Kim. J., Philosophy of Mind, Westview Press, 2006.

[13]. Lycan. W.G., Consciousness and Experience, Cambridge, Mass., M.I.T. Press, 1996.

[14]. Place. U.T., 'Is Consciousness a Brain Process?', British Journal of Psychology, 47, 44-50, 1956

[15]. Place. U.T., 'Materialism as a Scientific Hypothesis', Philosophical Review, 69, 101-104, 1960.

[16]. Rosenthal. D.M., 'A Theory of Consciousness'. In Block, N., Flanagan, O. and Güzeldere, G. (eds) The Nature of Consciousness, Cambridge, Mass., MIT Press, 1996.

[17]. U.T. Place, Identifying the Mind, (New York, Oxford University Press, 2004).

[18]. D.Lewis, Philosophical Papers, Vol. 1, Oxford, Oxford University Press, 1983.

[19]. D.M.Armstrong, The Headless Woman Illusion and the Defence of Materialism, Analysis, 29, 1968b, 48-49.

[20]. S.Kripke, Naming and Necessity, (Cambridge, Mass., Harvard University Press, 1980). 